\title{
Atuação dos profissionais de enfermagem frente às mulheres vítimas de violência doméstica
}

\author{
Performance of nursing professionals in front of women victims of domestic violence \\ Desempeño de profesionales de enfermería frente a mujeres víctimas de violencia \\ doméstica
}

Renata de Lima Galvão ${ }^{1}$, Halley Ferraro Oliveira ${ }^{1}$, Maria Adriely Cunha Lima ${ }^{1 *}$, Tiago Almeida Costa1, Giovanna Freitas Munaretto ${ }^{1}$, Mariana Soares Faria ${ }^{1}$, Tatiane de Oliveira Santos ${ }^{1}$, Thaís Francielle Santana Vieira1, Fabiana de Oliveira Pinto², Márcia de Araújo Delgado².

\section{RESUMO}

Objetivo: Analisar os resultados das produções científicas acerca da assistência de enfermagem em mulheres vítimas de violência doméstica e conhecer os principais fatores relacionados a esta violência. Métodos: Trata-se de uma revisão integrativa da literatura, que tem por objetivo a reunião, análise e síntese de estudos pré-existentes sobre determinada temática, a coleta de dados foi feita através das bases de dados, LILACS, SciELO e BVS, foram selecionados 19 artigos publicados durante o período de 2013 a 2020. Resultados: Foi possível abordar o tema por meio dos fatores associados à violência doméstica, como pobreza e nível ensino. Além disso, foi notável que a violência doméstica ocorre de diferentes formas, como física, verbal, moral e psicológica. Referente aos profissionais de saúde, a atuação dos profissionais de enfermagem frente às mulheres vítimas da violência doméstica é imprescindível, até mesmo para auxílio na criação de políticas públicas. Considerações Finais: Foi identificado que os profissionais de enfermagem são os que identificam com maior facilidade situações e/ou casos de violência doméstica, uma vez que realizam uma assistência por tempo integral aos pacientes.

Palavras-chave: Violência doméstica, Profissionais de enfermagem, Saúde da mulher.

\begin{abstract}
Objective: Analyze the results of scientific productions about nursing care for women victims of domestic violence and learn about the main factors related to this violence. Methods: It is an integrative review of the literature, which aims to gather, analyze and synthesize pre-existing studies on a given theme, data collection was done through the databases, LILACS, SciELO and VHL, 19 were selected articles published during the period 2013 to 2020. Results: It was possible to approach the theme through factors associated with domestic violence, such as poverty and education level. In addition, it was notable that domestic violence occurs in different ways, such as physical, verbal, moral and psychological. Regarding health professionals, the role of nursing professionals in relation to women victims of domestic violence is essential, even to assist in the creation of public policies. Final Considerations: It was identified that nursing professionals are the ones who most easily identify situations and / or cases of domestic violence, since they provide full-time assistance to patients.
\end{abstract}

Keywords: Domestic violence, Nursing professionals, Women's health.

\section{RESUMEN}

Objetivo: Analizar los resultados de estudios científicos sobre el cuidado de enfermería a mujeres víctimas de violencia intrafamiliar y conocer los principales factores relacionados con esta violencia. Métodos: Es una revisión integradora de la literatura, que tiene como objetivo recopilar, analizar y sintetizar estudios preexistentes sobre un tema determinado, la recolección de datos se realizó a través de las bases de datos, LILACS, SciELO y BVS, se seleccionaron 19 artículos publicados durante el período 2013 a 2020.

${ }^{1}$ Universidade Tiradentes (UNIT), Aracaju - SE. *E-mail: mariaadrielycunha@hotmail.com.

2 Universidade Estácio de Sá, Aracaju - SE. 
Resultados: Fue posible abordar el tema a través de factores asociados a la violencia intrafamiliar, como la pobreza y el nivel educativo. Además, fue notable que la violencia doméstica se presenta de diferentes formas, como física, verbal, moral y psicológica. En cuanto a los profesionales de la salud, el papel de los profesionales de enfermería frente a las mujeres víctimas de violencia intrafamiliar es fundamental, incluso para ayudar en la creación de políticas públicas. Consideraciones Finales: Se identificó que los profesionales de enfermería son los que identifican con mayor facilidad situaciones y/o casos de violencia intrafamiliar, ya que brindan atención en tiempo completo a los pacientes.

Palabras clave: Violencia doméstica, Profesionales de enfermería, Salud de la mujer.

\section{INTRODUÇÃO}

Ocorre um elevado número nos índices de violência, tanto no Brasil quanto no mundo, e tal situação causa impacto na vida do indivíduo, família e coletividade transformando-se em uma prioridade da saúde pública mundial, uma vez que, devido a sua alta complexidade ao incluir a conscientização e cooperação de toda a comunidade (GARBIN CAS, et al., 2015). A violência é uma temática muito complexa, multicausal e controversa, onde pode ser realizada de múltiplas formas, que pode ocorrer devido a vários fatores e que engloba a família como um todo (ARAUJO FILHO ACA, et al., 2016).

A violência doméstica é entendida como o uso de maneira intencional da força física e do poder, seja propriamente dito ou em forma de ameaça, contra a si mesmo ou à outra pessoa, grupo, ou comunidade que possa ocasionar e/ou ocasione lesão, danos emocionais e psicológicos e morte ao indivíduo (CARPANEZ TG, et al., 2019). De acordo com Leite FMC, et al. (2017) e Silva NNF, et al. (2017), pressupõem-se que de $10 \%$ a $50 \%$ das mulheres mundialmente já foram acometidas por algum episódio de violência física em determinado momento da sua vida. Esse evento está relacionado com inúmeros fatores, tais como, do próprio indivíduo, sociais, culturais, ambientais e relacionais.

Nesse interim, o profissional de saúde que atende a mulher vítima de violência deve ser capacitado, a fim de prestar um atendimento que busque a resolução do problema, e auxilie na diminuição do ciclo de violência, e possibilite que os casos de menor gravidade não evoluam para situações mais graves. Além disso, os profissionais, principalmente a equipe de enfermagem, deve proporcionar uma assistência qualificada e individualizada, com foco na mulher e na criação de confiança entre o profissional e a paciente (SILVA NNF, et al., 2017; ABDOUNI MK, et al., 2017).

A respeito dos tipos de violência doméstica, há 3 formas comuns contra as mulheres: física, psicológica e sexual. Sendo que a física condiz ao dano ou tentativa de causar dano através da força física, de instrumentos/armas que possam causar lesões nas mulheres, tantos internas (fraturas) como externas (cortes, hematomas), por exemplo, socos e pontapés.

A violência sexual é toda ação na qual há obrigação de realizar práticas sexuais contra a vontade da pessoa, através da força física, da intimidação e, até mesmo, do uso de armas e de drogas, é válido ressaltar que o fato do ato sexual, muitas vezes, ser visto como um dever conjugal, sendo que a mulher teria a obrigação de ter relações quando solicitado, independentemente de sua vontade, é um dos fatores que facilita a ocorrência desse tipo de violência (SILVA LL, et al., 2007).

Já a violência psicológica ocorre quando há ação ou omissão que pode causar ou causa prejuízo à autoestima, à identidade ou ao desenvolvimento pessoal, como ameaças, humilhações e chantagem, sendo a forma mais difícil de identificar, por vezes, devido os momentos intercalados de agressões e de afeto.

Esses comportamentos, muitas vezes, visam manter/exercer um controle do agressor sobre a mulher, tendo início como tensões normais dos relacionamentos, por exemplo, causadas por problemas financeiros e por diferenças de opinião, as quais aumentam tornando-se uma violência psicológica.

Ademais, acredita-se que haja fatores de risco para esse tipo de violência, como a opressão causada pelo capitalismo, o machismo, a educação diferenciada, o consumo de álcool e drogas, o estresso e o cansaço. É válido mencionar que a violência psicológica estar bastante associada com a física (SILVA JA, et al., 2007; FONSECA PM e LUCAS TNS, 2006). 
No que tange os profissionais de saúde, estes devem estar atentos aos aspectos psicológicos e sociais da paciente que relata uma queixa biológica na tentativa de identificá-la como vítima de violência doméstica haja vista que a denúncia, por parte da mulher, é um evento incomum (SCHRAIBER LB, 2007).

Para queixas de caráter mais crônico como, por exemplo, infecções sexualmente transmissíveis (IST's) deve-se considerar a possibilidade de violência sexual, assim como, naquelas de caráter mais agudo como, por exemplo, lesões de pele deve-se considerar a possibilidade de violência física (MINISTÉRIO DA SAÚDE, 2002).

Segundo a Organização Mundial da Saúde (OMS), em 2013, a prevalência de violência física e/ou sexual causada pelo parceiro íntimo contra mulher foi de $30 \%$, mundialmente (WORLD HEALTH ORGANIZATION, 2013). Dado isso, é válido mencionar que a violência contra mulher é uma violação dos direitos humanos, além de um problema de saúde pública. Ademais, sabe-se que no Brasil há um elevado número de mulheres vítimas de violência doméstica.

Nesse cenário, faz-se premente que o profissional de saúde, sobretudo o profissional de enfermagem, que por muitas vezes é o primeiro contato, na atenção primária, da paciente com o serviço de saúde esteja apto para identificar, e assim notificar, uma vítima da violência doméstica, mas também para prestar a conduta adequada a esse tipo de paciente já que é imprescindível que a busca pelo serviço de saúde não se apresente como mais um evento negativo para essa mulher (GARBIN CAS, et al., 2015).

O interesse por esse estudo surgiu da necessidade de discutir os fatores associados a violência doméstica e as dificuldades encontradas pelos profissionais de saúde no atendimento a essas pacientes. Por tanto, o estudo justifica-se, em decorrência da necessidade de identificar a importância da assistência qualificada as pacientes mulheres vítimas de violência.

Assim, o presente estudo tem como objetivo analisar os resultados das produções científicas acerca da assistência de enfermagem em mulheres vítimas de violência doméstica e conhecer os principais fatores relacionados a esta violência.

\section{MÉTODOS}

Trata-se de uma revisão integrativa da literatura, que tem por objetivo a reunião, análise e síntese de estudos pré-existentes sobre determinada temática, de forma ordenada e sistemática, e tem a finalidade de aprofundar e debater sobre o tema a ser investigado.

Tal revisão divide-se em seis etapas: identificação do tema e seleção da hipótese ou questão norteadora; estabelecimento de critérios para inclusão e exclusão das produções científicas; definição das informações a serem extraídas dos estudos; avaliação das produções incluídas na revisão integrativa; interpretação dos resultados; e pôr fim a apresentação da revisão/síntese do conhecimento (MENDES KDS, et al., 2008).

Para realização da revisão integrativa foi estabelecida a questão norteadora: Qual a assistência dos profissionais de enfermagem frente à violência doméstica, que esteja publicada em revistas científicas entre 2013 a 2020? Quais são os fatores relacionados a essa violência?

O levantamento bibliográfico foi feito por meio de produções científicas que abordaram o tema violência doméstica e atuação do enfermeiro, publicadas durante o período de 2013 a abril de 2020. A coleta de dados foi feita através das bases de dados, Literatura Latino-Americana e do Caribe em Ciências da Saúde (LILACS), Scientific Electronic Library Online (SciELO) e Biblioteca Virtual em Saúde (BVS). Para a busca das produções científicas foram utilizados os Descritores em Ciência e Saúde (DeCS): Violência Domésticaand Saúde da Mulher and Violência contra a Mulher and Papel do Profissional de Enfermagem.

Os critérios de seleção e inclusão das produções científicas obedeceram aos seguintes parâmetros: originais disponíveis na íntegra, nos idiomas português e inglês, publicados entre 2013 a 2020. E serão excluídos os resumos expandidos, cartilhas e artigos que não contemplem a temática proposta e ano de publicação. 
Das 116 produções científicas pesquisadas, após aplicar os critérios de inclusão e de exclusão, foi realizado leitura do resumo e do título, para assim escolher os artigos. Após isso, apenas 17 estudos foram pertinentes para a realização deste estudo (Figura 1). A fim de melhorar a compreensão dos artigos foi construída uma planilha para análise dos resultados a partir da leitura e categorização dos conteúdos, organizados nos resultados.

Figura 1 - Estrutura do desenvolvimento da pesquisa,

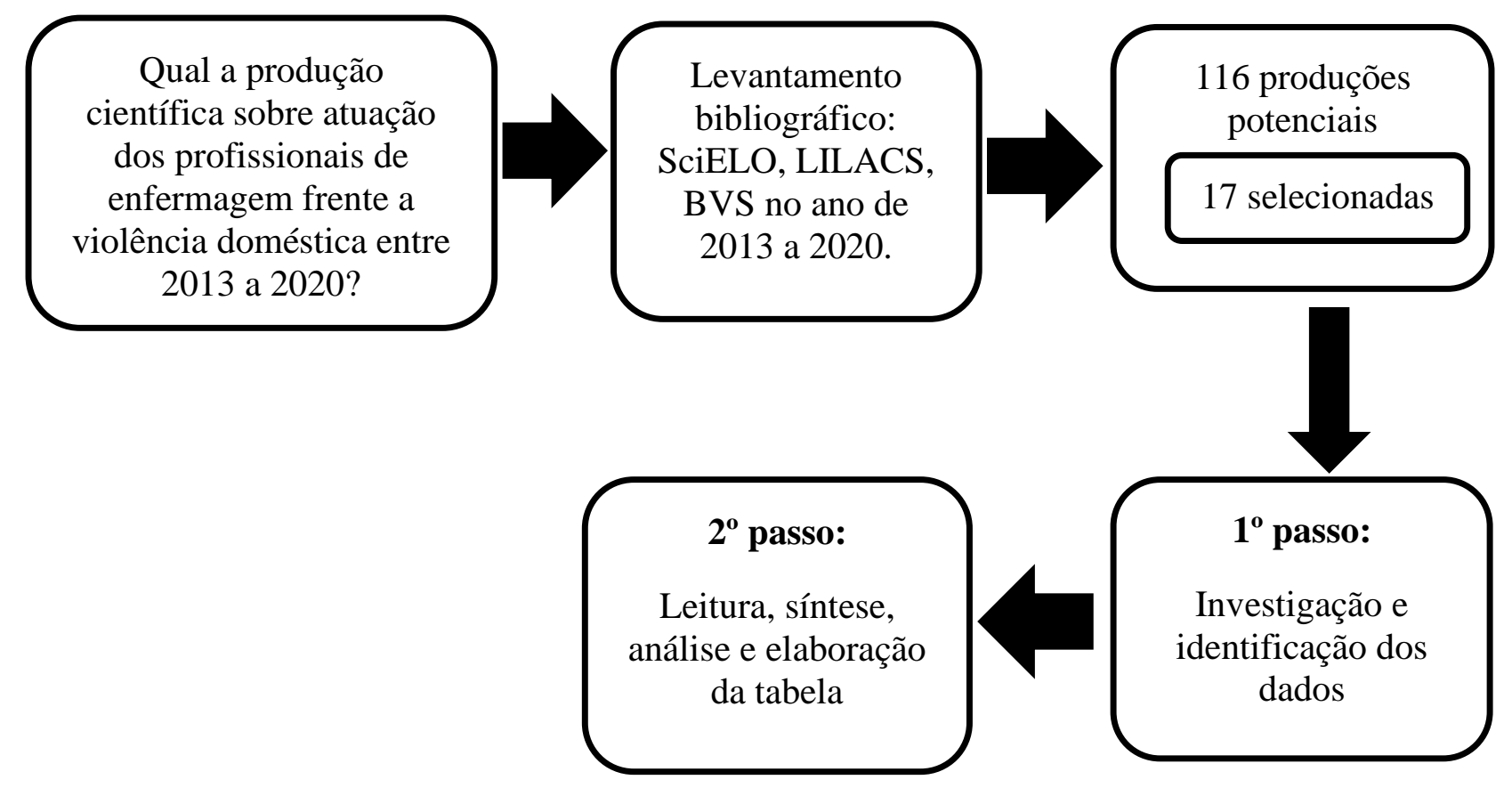

Fonte: GALVÃO RL, et al., 2020.

Foi elaborado um instrumento de coleta de dados, a fim de responder à questão norteadora deste estudo, composto pelos seguintes itens: autor/ano, título, objetivo e resultados. Após a leitura e análise das 17 produções científicas foi realizada a organização das temáticas em duas vertentes: Fatores Associados à Violência Doméstica; e Atuação dos Profissionais de Enfermagem frente às mulheres vítimas de Violência Doméstica. Por trata-se de um estudo de revisão, com informações de domínio público, não se faz necessário nem o registro nem a avaliação do Sistema Nacional de Ética em Pesquisa conforme a Resolução 510/16 do Conselho Nacional de Saúde de 7 de abril de 2016 (BRASIL, 2016).

\section{RESULTADOS}

A partir da busca de dados foram selecionados 17 artigos que atendiam aos critérios de inclusão. Sendo que 11 abordaram também fatores de risco associados à violência doméstica e seus tipos (Quadro 1). Referente aos fatores de risco foi citado a questão do alcoolismo pelo parceiro, ademais, notou-se que idade e escolaridade, por exemplo, estão relacionados com um aumento do número de casos. Outrossim, foi relatado a presença, principalmente, de violência psicológica e física, sendo que apenas $2(11,7 \%)$ artigos relataram violência sexual (LEITE FMC, et al., 2017; PERALVA TR, et al, 2016).

No que diz respeito aos profissionais de enfermagem, 6 trabalhos tiveram a abordagem direcionada para atuação deles (Quadro 2). Foi elaborada a questão da falta de informação dos profissionais de saúde acerca da sua conduta perante os casos de violência doméstica em mulheres e suas obrigações, sendo que alguns artigos mencionaram a prática de capacitações e oficinas educativas, para que, por meio disso, haja uma maior conscientização sobre essa temática, apesar da dificuldade de adesão desses profissionais por causa, principalmente, da carga horário do trabalho. Ademais, os profissionais de enfermagem observam a necessidade da abordagem multidisciplinar, não só com a vítima, mas também com seus familiares (primordialmente, os filhos), que também sofrem danos. 
Quadro 1 - Tipos de violência doméstica e seus fatores de risco.

\begin{tabular}{|c|c|c|c|}
\hline Autores/Ano & Título & Objetivos & Resultados \\
\hline $\begin{array}{l}\text { ANDRADE } \\
\text { RFV, et al., } \\
\quad 2016 .\end{array}$ & $\begin{array}{l}\text { Prevalência e fatores associados à } \\
\text { violência entre parceiros íntimos } \\
\text { após a revelação do diagnóstico de } \\
\text { doenças sexualmente } \\
\text { transmissíveis ao parceiro. }\end{array}$ & $\begin{array}{l}\text { Investigar a prevalência e os fatores } \\
\text { associados à perpetração de violência por } \\
\text { parceiro íntimo em portadores de doenças } \\
\text { sexualmente transmissíveis. }\end{array}$ & $\begin{array}{l}\text { A bebida alcoólica contribui para o uso da violência por } \\
\text { parceiro íntimo, foi identificado que as pessoas que } \\
\text { ingeriam álcool possuíam } 3 \text { vezes mais chances de } \\
\text { praticarem violência contra o seu parceiro ao revelarem } \\
\text { que possuem alguma doença sexualmente transmissível. }\end{array}$ \\
\hline $\begin{array}{l}\text { BARROS EN, } \\
\text { et al., } 2016 .\end{array}$ & $\begin{array}{l}\text { Prevalência e fatores associados à } \\
\text { violência por parceiro íntimo em } \\
\text { mulheres de uma comunidade em } \\
\text { Recife/Pernambuco, Brasil. }\end{array}$ & $\begin{array}{l}\text { Investigar a prevalência e os fatores } \\
\text { associados à VPI em mulheres de uma } \\
\text { comunidade na Cidade r de } \\
\text { Recife/Pernambuco. }\end{array}$ & $\begin{array}{l}\text { A maioria das mulheres que sofreram violência doméstica } \\
\text { eram jovens, possuíam oito anos ou mais de estudo, sem } \\
\text { filhos, sem emprego, não tinham companheiro na época da } \\
\text { coleta de dados e já usaram drogas e álcool. }\end{array}$ \\
\hline $\begin{array}{l}\text { BOZZO ACB, et } \\
\text { al., } 2017 .\end{array}$ & $\begin{array}{l}\text { Violência doméstica contra a mulher: } \\
\text { caracterização dos casos notificados } \\
\text { em um município do interior paulista. }\end{array}$ & $\begin{array}{l}\text { Identificar o perfil das mulheres de violência } \\
\text { doméstica no município de Ribeirão Preto. }\end{array}$ & $\begin{array}{l}\text { Foi observado que a maioria das vítimas tinham raça } \\
\text { branca, } 3996(70,81 \%) \text { dos casos, houve predominância } \\
\text { do ensino fundamental completo- } 1077 \text { (19,09\%). Já em } \\
\text { relação ao tipo de violência, constatou-se maior } \\
\text { porcentagem na violência psicológica/moral- } 4640 \\
(82,33 \%) \text {, seguida da violência física- } 2792(49,48 \%) \text { dos } \\
\text { casos. }\end{array}$ \\
\hline $\begin{array}{l}\text { CARPANEZ } \\
\text { TG, et al., } 2019 .\end{array}$ & $\begin{array}{l}\text { Violência entre parceiros íntimos e } \\
\text { uso de álcool: estudo qualitativo com } \\
\text { mulheres da cidade de Juiz de Fora } \\
\text { - MG. }\end{array}$ & $\begin{array}{l}\text { Analisar a relação entre o consumo de } \\
\text { álcool e a ocorrência de violência entre } \\
\text { parceiros íntimos segundo o ponto de vista } \\
\text { das mulheres vítimas de violência. }\end{array}$ & $\begin{array}{l}\text { A maioria das entrevistadas acreditam que possui relação } \\
\text { entre o consumo de álcool e as mudanças de } \\
\text { comportamento do seu parceiro e consequentemente a } \\
\text { ocorrência de episódios de violência doméstica. }\end{array}$ \\
\hline $\begin{array}{l}\text { COLOSSI PM, } \\
\text { et al., } 2015 .\end{array}$ & $\begin{array}{l}\text { Violência conjugal: prevalência e } \\
\text { fatores associados. }\end{array}$ & $\begin{array}{l}\text { Descrever a violência no casal, bem como } \\
\text { analisar possíveis correlações com } \\
\text { variáveis sociodemográficas. }\end{array}$ & $\begin{array}{l}\text { No estudo foi identificado que quanto menor a idade, maior } \\
\text { os números de agressão física e psicológica, tais dados } \\
\text { possibilitam a reflexão de que a maturidade emocional leva } \\
\text { o indivíduo a pensar mais e refletir sobre as suas ações ao } \\
\text { vivenciarem situações de conflito. }\end{array}$ \\
\hline $\begin{array}{l}\text { COSTA MC, et } \\
\text { al., } 2014 .\end{array}$ & $\begin{array}{l}\text { Representações sociais da violência } \\
\text { contra mulheres rurais: desvelando } \\
\text { sentidos em múltiplos olhares. }\end{array}$ & $\begin{array}{l}\text { Conhecer de forma descritiva e analisar, } \\
\text { em cenários rurais do Rio Grande do Sul, } \\
\text { as representações sociais da violência } \\
\text { contra as mulheres na perspectiva de } \\
\text { gestores municipais, profissionais e } \\
\text { trabalhadores. }\end{array}$ & $\begin{array}{l}\text { Os profissionais de saúde identificaram que para a maioria } \\
\text { das mulheres que residem no meio rural, a violência é um } \\
\text { destino. Nessa perspectiva, a violência é vista nos serviços } \\
\text { de saúde de forma natural devido as tradições } \\
\text { socioculturais. }\end{array}$ \\
\hline
\end{tabular}

REAS/EJCH | Vol.13(1) | e5165 | DOI: https://doi.org/10.25248/reas.e5165.2021 Página 5 de 10 


\section{Revista Eletrônica Acervo Saúde / Electronic Journal Collection Health | ISSN 2178-2091}

\begin{tabular}{|c|c|c|c|}
\hline Autores/Ano & Título & Objetivos & Resultados \\
\hline $\begin{array}{l}\text { GARCIA LP, et } \\
\text { al., } 2016 .\end{array}$ & $\begin{array}{l}\text { Violência doméstica e familiar contra } \\
\text { a mulher: estudo de casos e } \\
\text { controles com vítimas atendidas em } \\
\text { serviços de urgência e emergência. }\end{array}$ & $\begin{array}{l}\text { Identificar fatores associados ao } \\
\text { atendimento por violência doméstica e } \\
\text { familiar entre vítimas atendidas em serviços } \\
\text { de urgência e emergência no Brasil. }\end{array}$ & $\begin{array}{l}\text { Em 2011, } 16.256 \text { mulheres usaram os serviços do Sistema } \\
\text { de Vigilância de Violências e Acidentes (VIVA), destas, } \\
5.104(31,4 \% \text { ) eram menores de idade. Ao analisar os tipos } \\
\text { de agressões sofridas, a violência física foi predominante, } \\
\text { com } 97,4 \% \text {, entre os prováveis autores da agressão, a } \\
\text { maioria era os companheiros ou ex-companheiros, } 51,5 \% \text {. }\end{array}$ \\
\hline $\begin{array}{l}\text { LEITE FMC, et } \\
\text { al., } 2017 .\end{array}$ & $\begin{array}{l}\text { Violência contra a mulher em Vitória, } \\
\text { Espírito Santo, Brasil. }\end{array}$ & $\begin{array}{l}\text { Estimar a prevalência e os fatores } \\
\text { associados às violências psicológica, física } \\
\text { e sexual nas mulheres vítimas de violência } \\
\text { perpetrada pelo parceiro íntimo atendidas } \\
\text { em serviços de atenção primária. }\end{array}$ & $\begin{array}{l}\text { A violência mais frequente foi a psicológica, seguida da } \\
\text { física e, por fim, a sexual. Pode-se identificar também que } \\
\text { tanto as mulheres quanto os profissionais de saúde } \\
\text { possuíam dificuldades em dialogar sobre a violência. }\end{array}$ \\
\hline $\begin{array}{l}\text { PERALVA TR, } \\
\text { et al, } 2016 .\end{array}$ & $\begin{array}{l}\text { Violência doméstica na percepção } \\
\text { de enfermeiros de serviço de } \\
\text { emergência. }\end{array}$ & $\begin{array}{l}\text { Conhecer a percepção do enfermeiro que } \\
\text { atua no serviço de emergência hospitalar } \\
\text { sobre violência doméstica. }\end{array}$ & $\begin{array}{l}\text { No estudo, foi identificado que os principais casos de } \\
\text { violência doméstica foram, as verbais, as físicas como } \\
\text { "tapas" e "murros" e por último a violência sexual. A maioria } \\
\text { dos profissionais que participaram das entrevistas } \\
\text { demonstraram não possuir conhecimento sobre o tema } \\
\text { proposto, a violência doméstica. }\end{array}$ \\
\hline $\begin{array}{l}\text { SILVA LEL e } \\
\text { OLIVEIRA } \\
\text { MLC, } 2016 .\end{array}$ & $\begin{array}{l}\text { Características epidemiológicas da } \\
\text { violência contra a mulher no Distrito } \\
\text { Federal, } 2009 \text { a } 2012 \text {. }\end{array}$ & $\begin{array}{l}\text { Descrever as características } \\
\text { epidemiológicas dos casos de violência } \\
\text { contra a mulher notificados no Distrito } \\
\text { Federal, Brasil, no período 2009-2012. }\end{array}$ & $\begin{array}{l}\text { Durante o período estudado pode-se observar } 1.924 \text { casos } \\
\text { suspeitos ou confirmados de violência contra a mulher } \\
\text { entre } 18 \text { a } 59 \text { anos, com o crescimento dos números de } \\
\text { casos em relação aos anos estudados, já que em } 2009 \\
\text { ocorrem } 357 \text { e em } 2012 \text { ocorreram } 763 \text { casos, aumentando } \\
113 \% \text {. }\end{array}$ \\
\hline $\begin{array}{l}\text { SOUZA JÁ, et } \\
\text { al., } 2016 .\end{array}$ & $\begin{array}{l}\text { Fatores associados à violência } \\
\text { conjugal em um grupo de mulheres } \\
\text { no município de João Pessoa- } \\
\text { Paraíba. }\end{array}$ & $\begin{array}{l}\text { Investigar os fatores que se associam à } \\
\text { violência conjugal em um grupo de } \\
\text { mulheres no município de João Pessoa- } \\
\text { Paraíba. }\end{array}$ & $\begin{array}{l}\text { No estudo foi identificado que } 63,2 \% \text { das mulheres que } \\
\text { sofreram violência possuíam o nível fundamental de } \\
\text { ensino, além disso, a pobreza foi o fator que causa conflito } \\
\text { familiares e podem transcorrer para a violência contra a } \\
\text { mulher. }\end{array}$ \\
\hline
\end{tabular}

Fonte: GALVÃO RL, et al., 2020.

REAS/EJCH | Vol.13(1) | e5165 | DOI: https://doi.org/10.25248/reas.e5165.2021 Página 6 de 10 
Quadro 2 - Fatores de risco associados à violência doméstica.

\begin{tabular}{|c|c|c|c|}
\hline Autores/Ano & Título & Objetivos & Resultados \\
\hline $\begin{array}{l}\text { ACOSTA DF, } \\
\text { et al., } 2017 .\end{array}$ & $\begin{array}{l}\text { Aspectos éticos e legais no } \\
\text { cuidado de enfermagem às } \\
\text { vítimas de violência doméstica. }\end{array}$ & $\begin{array}{l}\text { Analisar os conhecimentos de } \\
\text { enfermagem hospitalares sobre os } \\
\text { aspectos éticos e legais no cuidado de } \\
\text { enfermagem as vítimas de violência } \\
\text { doméstica. }\end{array}$ & $\begin{array}{l}\text { A maioria dos profissionais de saúde não possuíam conhecimento } \\
\text { acerca do assunto, violência doméstica, nem quais ações } \\
\text { deveriam tomar quando confrontadas com essa situação. Os } \\
\text { mesmos argumentaram que não trabalhavam nessa área" e que } \\
\text { possuem pouca experiência profissional. }\end{array}$ \\
\hline $\begin{array}{l}\text { ACOSTA DF, } \\
\text { et al., } 2018 .\end{array}$ & $\begin{array}{l}\text { Representações sociais de } \\
\text { enfermeiras acerca da violência } \\
\text { doméstica contra a mulher: } \\
\text { estudo com } \quad \text { abordagem } \\
\text { estrutural. }\end{array}$ & $\begin{array}{l}\text { Analisar a estrutura e os conteúdos das } \\
\text { representações sociais de enfermeiras } \\
\text { acerca da violência doméstica contra a } \\
\text { mulher. }\end{array}$ & $\begin{array}{l}\text { As enfermeiras que foram entrevistadas identificaram que a VD } \\
\text { não se limitava apenas a vítima, ela causava danos nos filhos e } \\
\text { outros familiares. Por meio desses dados, é essencial que os } \\
\text { serviços de saúde proporcionem uma assistência linear que visem } \\
\text { a promoção e proteção da saúde da mulher, filhos e da família. }\end{array}$ \\
\hline $\begin{array}{l}\text { FREITAS } \\
\text { RJM, et al., } \\
2017 \text {. }\end{array}$ & $\begin{array}{l}\text { Atuação dos enfermeiros na } \\
\text { identificação e notificação dos } \\
\text { casos de violência contra a } \\
\text { mulher. }\end{array}$ & $\begin{array}{l}\text { Compreender a atuação dos enfermeiros } \\
\text { na identificação e notificação dos casos de } \\
\text { violência contra a mulher, nas Unidades de } \\
\text { Pronto Atendimento (UPA's). }\end{array}$ & $\begin{array}{l}\text { Por meio das entrevistas pode-se observar que muitos } \\
\text { profissionais de saúde, entre eles, os enfermeiros, constataram } \\
\text { insegurança em relação a identificação dos casos de violência } \\
\text { quando as vítimas não expõem livremente a situação, e mostraram } \\
\text { não conhecer perfeitamente o processo de notificação. }\end{array}$ \\
\hline $\begin{array}{l}\text { GARBIN } \\
\text { CAS, et al., } \\
2015 .\end{array}$ & $\begin{array}{l}\text { Desafios do profissional de } \\
\text { saúde na notificação da } \\
\text { violência: obrigatoriedade, } \\
\text { efetivação e encaminhamento. }\end{array}$ & $\begin{array}{l}\text { Instruir o profissional de saúde quanto ao } \\
\text { reconhecimento da obrigatoriedade de } \\
\text { notificação da violência e aos meios } \\
\text { disponíveis para sua efetivação e devido } \\
\text { encaminhamento. }\end{array}$ & $\begin{array}{l}\text { Por meio da conscientização sobre a importância da notificação e } \\
\text { as capacitações contínuas para os profissionais de saúde sobre as } \\
\text { situações de violência, proporciona subsídios para a elaboração de } \\
\text { políticas públicas em saúde mais eficientes e eficazes. }\end{array}$ \\
\hline $\begin{array}{l}\text { LEITE JT, et } \\
\text { al., } 2016 .\end{array}$ & $\begin{array}{l}\text { Enfrentamento da violência } \\
\text { doméstica contra crianças e } \\
\text { adolescentes na perspectiva de } \\
\text { enfermeiros da atenção básica. }\end{array}$ & $\begin{array}{l}\text { Analisar as ações relatadas por } \\
\text { enfermeiros da atenção básica no } \\
\text { enfrentamento da violência doméstica } \\
\text { contra crianças e adolescentes. }\end{array}$ & $\begin{array}{l}\text { Foi identificado por meio de relatos dos enfermeiros que havia } \\
\text { iniciativa do poder público para a realização de capacitações, } \\
\text { entretanto os profissionais de saúde enfrentavam dificuldades para } \\
\text { participar das atividades devido, em especial, a sobrecarga de } \\
\text { trabalho. }\end{array}$ \\
\hline $\begin{array}{l}\text { SILVA PLN, } \\
\text { et al., } 2016 .\end{array}$ & $\begin{array}{l}\text { Práticas educativas sobre } \\
\text { violência contra a mulher na } \\
\text { formação de universitários. }\end{array}$ & $\begin{array}{l}\text { Analisar as práticas educativas sobre } \\
\text { violência contra a mulher na formação } \\
\text { profissional de estudantes universitários. }\end{array}$ & $\begin{array}{l}\text { Através das oficinas educativas sobre VD para os participantes do } \\
\text { estudo, eles relataram que a troca de informações de uns com os } \\
\text { outros auxiliaram no ganho de conhecimento. Além disso, } \\
\text { observaram a importância da troca de informações entre os } \\
\text { profissionais. Logo, uma equipe multidisciplinar possibilita uma } \\
\text { assistência mais qualificada e integral. }\end{array}$ \\
\hline
\end{tabular}

Fonte: GALVÃO RL, et al., 2020.

REAS/EJCH | Vol.13(1) | e5165 | DOI: https://doi.org/10.25248/reas.e5165.2021 Página 7 de 10 


\section{DISCUSSÃO}

\section{Fatores Associados à Violência Doméstica}

Por meio de dados epidemiológicos verifica-se que os maiores índices de ocorrência de violência doméstica contra a mulher são exercidos pelo próprio parceiro íntimo, no seu próprio lar. Sendo assim, muitos casos não são notificados nem identificados (ACOSTA DF, et al., 2018). No estudo realizado por Silva LEL e Oliveira MLC (2016), foi observado que a maioria das mulheres que sofreram violência eram jovem na sua residência, tendo como principal tipo a violência física, onde os parceiros utilizaram de força corporal e/ou espancamento para causar lesões nas mulheres, com $46,8 \%$ dos casos, após encontra-se a violência sexual com $22,5 \%$ e a psicológica com $20,3 \%$ dos casos.

Esses dados são corroborados pela pesquisa realizada por Garcia LP, et al. (2016), em serviços de urgência e emergência vinculados ao Sistema Único de Saúde, onde constataram que $97,4 \%$ das mulheres sofreram violência física, destas $60,7 \%$ foram através da força corporal/espancamento, $20,9 \%$ por objeto perfurocortante e $11,9 \%$ por meio de objeto contundente.

Segundo Silva LEL e Oliveira MLC (2016); Leite FMC, et al. (2017), existem vários fatores relacionados a violência doméstica contra a mulher, sendo eles: o uso de álcool e/ou drogas pelo parceiro, os antecedentes familiares de violência, o nível socioeconômico baixo, e o instável apoio social. Ademais, o principal fator relacionado à violência doméstica é a desigualdade oriunda da relação tradicional de gênero, onde a agressão é utilizada como estratégia para manter o poder masculino sobre a mulher.

Outro fator associado evidenciado em estudos, como os de Souza JA, et al. (2016) e Barros EM, et al. (2016), foi a reincidência da violência, onde evidenciaram que as mulheres que sofreram anteriormente violência oriunda de qualquer indivíduo do seu ciclo familiar possui maiores chances de sofrer a violência doméstica conjugal. Ao analisar as mulheres que denunciam agressão na delegacia especializada de atendimento, a maioria afirma já ter sofrido agressão anteriormente.

Mulheres que sofrem a violência podem sofrer inúmeras consequências durante todo a sua vida, tais como a propensão a vida criminosa, problemas psicológicos que podem ocasionar o comportamento suicida e de autoflagelação, além de poder desenvolver ansiedade, psicose, depressão, distúrbios de personalidade e dificuldades nas relações interpessoais e profissionais. Além disso, boa parte das vítimas utilizam o uso de substâncias entorpecentes e se envolvem com o meio de criminalidade a fim de solucionar os problemas sociais, entretanto essas ações só alimentam o ciclo de violência (LEITE JT, et al., 2016).

O uso de bebida alcoólica colabora para as ações de agressão e eleva os índices de ocorrência e a gravidade da violência doméstica, no estudo de Andrade RFV, et al. (2016) pode-se observar que os indivíduos que ingeriam álcool possuíam duas vezes mais chances de realizar agressão ao parceiro. Em outro estudo realizado por Carpanez TG, et al. (2019), foi observado também uma correlação entre os casos de violência e o uso de álcool, $40 \%$ das mulheres que sofreram violência doméstica o parceiro tinha ingerido álcool anteriormente.

Já quanto ao uso de substâncias pelas mulheres, na literatura há descrição para o aumento da prevalência de violência doméstica em tal grupo, do qual a violência física e psicológica está mais relacionada às mulheres fumantes enquanto a violência sexual associa-se mais, frequentemente, às usuárias de drogas (BARROS EN, 2016). Em contrapartida, é válido ressaltar que a violência doméstica predispõe que a vítima inicie o uso ou abuso de drogas lícitas ou ilícitas na tentativa de fuga daquele evento negativo o qual ela encontra-se exposta (SAPORI LF e SENA LL, 2012; EL-BASSEL N, et al., 2005).

Para Souza JA, et al. (2016), a pobreza é uma importante condição que pode causar conflitos nas relações familiares, e podem desencadear a violência contra a mulher dentro da sua residência. A fome, falta de educação, de lazer e a ausência da qualidade de vida são razões que proporcional a instabilidade emocional entre os integrantes da família. Para Jewkes $\mathrm{R}$, et al. (2002), em relação a condição socioeconômica, há uma maior vulnerabilidade para as mulheres que possuem baixa renda por consequência de uma dependência financeira que pode se estabelecer entre ela e seu agressor colocando-a em um lugar de submissão e desencorajando-a à realizar uma denúncia e por fim nesse ciclo, com corrobora Fortuna SLA (2011). 
Para Leite FMC, et al. (2017), a prevalência da violência doméstica é influenciada também pelo nível de escolaridade da mulher uma ver que, como corrobora Adeodato VG, et al. (2005), um maior esclarecimento promove, na mulher, tanto uma redução na aceitação do seu lugar de vítima quanto maior probabilidade de que ela atinja sua independência mediante um emprego de boa remuneração. Para Colossi PM, et al. (2015), a maturidade emocional pode reduzir os índices de violência doméstica, uma vez que no seu estudo foi identificado que quanto menor a idade, maior são os números de violência física e psicológica. $O$ que demonstra que a maior idade pode estar relacionada a maior tolerância, e resolução de conflitos de forma não violenta.

\section{Atuação dos Profissionais de Enfermagem frente às mulheres vítimas de Violência Doméstica}

Os serviços de saúde são essenciais nas ações de enfrentamento da violência, já que são nesses ambientes que, na maioria das vezes, as vítimas recebem o primeiro atendimento e/ou cuidados. Entretanto, percebe-se que muitos profissionais de saúde não identificam os agravos decorrentes dessa causa, o que evidencia a incapacidade de identificar e registras os casos de violência doméstica (GARBIN LP, et al., 2015).Os profissionais de saúde da enfermagem necessitam conhecer a rede de apoio à vítima no município onde trabalha, para que possa encaminhá-la e orientá-la em relação aos serviços prestados e aos respaldos oferecidos pela lei, ajudando-as no enfrentamento e recuperação dos traumas sofridos, tanto psicológicos como físicos. Portanto, o profissional necessita prestar uma assistência de forma holística e humanizada (ACOSTA DF, et al., 2017).

A fim de desenvolver suas atribuições diante da complexidade da ocorrência, é imprescindível que o enfermeiro possua conhecimento acerca da violência doméstica e das inúmeras questões que permeiam esse problema, com o intuito de interceder de maneira estratégica na promoção, prevenção e reabilitação dessas vítimas (PERALVA TR, et al., 2016). Nesse interim, para Costa MC, et al. (2014), os profissionais de saúde da rede primária associam os casos de violência doméstica com outros fatores, tais como: o desemprego, a falta de diálogo nos relacionamentos, o uso de álcool e/ou drogas, o que constata as influências sociais e comunitárias nos casos de violência.

De acordo com Freitas RJM, et al. (2017), a identificação dos casos de violência ocorre na primeira etapa do processo de enfermagem, ou seja, no histórico e/ou coleta de dados. Portanto, o cuidado necessita ser planejado a fim de proporcionar segurança, respeito, acolhimento e satisfação das necessidades individuais da pessoa assistida. O acolhimento é primordial para a humanização do atendimento, e pode facilitar a coleta de todos os dados essenciais para a identificação das vítimas.

Acosta DF, et al. (2018), os profissionais de enfermagem, por assistirem os pacientes por tempo integral, são os que identificam com mais facilidade as situações de violência doméstica, auxiliando principalmente, na quebra do silêncio dessas vítimas através da orientação acerca dos serviços de apoio. Além disso, através dessa troca de informações entre o profissional de saúde e a mulher, ocorre o fortalecimento do vínculo e da confiança. No estudo realizado por Silva PLN, et al. (2016), constataram que a violência doméstica é uma temática complexa e que ocorre mundialmente, entretanto a capacitação dos profissionais de saúde sobre o tema ainda é falha. Nessa perspectiva, eles ressaltam a importância dos gestores e instituições de ensino capacitarem os profissionais e discentes de maneira multidisciplinar para assistir as vítimas de violência na sociedade.

Nessa perspectiva, Silva LEL e Oliveira MLC (2016), afirmam que o aperfeiçoamento da qualidade da informação e um dos componentes essenciais para proporcionar maior confiança e precisão na tomada de decisão por parte do profissional de saúde. Por isso, é primordial qualificar esses profissionais acerca do acolhimento a usuária vítima de violência doméstica e da maneira correta de preencher as Fichas de Notificação/Investigação Individual de Violência Doméstica, Sexual e/ou Outras Violências Interpessoais (FNIV).

Os profissionais de saúde e os outros profissionais que atendem a mulher vítima de violência doméstica deve atender e identificar as ocorrências de agressão, proporcionar auxílio e apoio e acatar o sigilo e as ações que desejam tomar em decorrência do episódio ocorrido. Além disso, é necessário que o profissional incentive o acesso a mulher vítima de violência aos serviços de saúde e de proteção contra a violência doméstica (BOZZO ACB, et al., 2017). 


\section{CONSIDERAÇÕES FINAIS}

Identificou-se que os profissionais de enfermagem são aqueles que identificam com maior facilidade situações e/ou casos de violência doméstica, uma vez que realizam uma assistência por tempo integral aos pacientes. Além disso, os profissionais por meio do diálogo e assistência conquistam a confiança da paciente, e proporciona um ambiente propício para que a mesma expresse a sua situação. A fim de prestar uma assistência qualificada, foi observado a importância das capacitações desses profissionais acerca da temática. Nessa perspectiva, recomenda-se a elaboração de novas pesquisas sobre a violência doméstica, com o intuito de identificar as situações que facilite e dificulte a atuação dos profissionais de enfermagem no atendimento a esses indivíduos.

\section{REFERÊNCIAS}

1. ABDOUNI MK, et al. Atuação da equipe de enfermagem no atendimento ambulatorial frente à mulher violentada. Revista REENVAP, 2017, 1 (4).

2. ACOSTA DF, et al. Aspectos éticos e legais no cuidado de enfermagem às vítimas de violência doméstica. Texto Contexto Enferm, 2017, 26 (3 e. 6770015).

3. ACOSTA DF, et al. Representações sociais de enfermeiras acerca da violência doméstica contra a mulher: estudo com abordagem estrutural. Revista Gaúcha Enferm, 2018, 39 (e. 61308).

4. ADEODATO VG, et al. Qualidade de vida e depressão em mulheres vítimas de seus parceiros. Rev Saude Publica 2005; 39 (1), 108-113

5. ANDRADE RFV, et al. Prevalência e fatores associados à violência entre parceiros íntimos após a revelação do diagnóstico de doenças sexualmente transmissíveis ao parceiro. Caderno Saúde Pública, 2016, 32 (7 e. 8715).

6. ARAUJO FILHO ACA, et al. Atuação do enfermeiro frente à violência doméstica contra a criança e o adolescente: revisão integrativa. UNIGRANRIO, 2016, 10 (3).

7. BARROS EN, et al. Prevalência e fatores associados à violência por parceiro íntimo em mulheres de uma comunidade em Recife/Pernambuco, Brasil. Ciência \& Saúde Coletiva, 2016, 21 (2), 591-598.

8. BOZZO ACB, et al. Violência doméstica contra a mulher: caracterização dos casos notificados em um município do interior paulista. Revista Enferm, 2017, 25 (e. 11173).

9. BRASIL. Resolução nํ 510, de 7 de abril de 2016, do Conselho Nacional de Saúde. Dispõe sobre as normas aplicáveis a pesquisas em Ciências Humanas e Sociais. Diário Oficial da União, Abr. 7. Brasília (DF); 2016.

10. CARPANEZ TG, et al. Violência entre parceiros íntimos e uso de álcool: estudo qualitativo com mulheres da cidade de Juiz de Fora - MG. Pesquisas e Práticas Psicossociais, 2019, 14 (2 e. 1550).

11. COLOSSI PM, et al. Violência conjugal: prevalência e fatores associados. Contextos Clínicos, 2015, 8 (1), 55-66.

12. COSTA MC, et al. Representações sociais da violência contra mulheres rurais: desvelando sentidos em múltiplos olhares. Revista Esc Enferm, 2014, 48 (2), 214-222.

13. EL-BASSEL N, et al. Relationship between drug abuse and intimate partner violence: a longitudinal study among women receiving methadone. Am J Public Health 2005; 95 (3), 465-470.

14. FREITAS RJM, et al. Atuação dos enfermeiros na identificação e notificação dos casos de violência contra a mulher. HU Revista, 2017, 43 (2), 91-97.

15. FONSECA PM, LUCAS TNS. Violência doméstica contra a mulher e suas consequências psicológicas. Salvador, 2006,24 f. Tese (Graduação em Psicologia)- Escola Bahiana de Medicina e Saúde Pública, Salvador, 2006.

16. FORTUNA SLA. As estratégias de enfrentamento da violência doméstica: um estudo sobre Guarapuava. Ex æquo 2011; 24:139-151

17. GARBIN CAS, et al. Desafios do profissional de saúde na notificação da violência: obrigatoriedade, efetivação e encaminhamento. Ciência \& Saúde Coletiva, 2015, 20 (6), 1879-1890.

18. GARCIA LP, et al. Violência doméstica e familiar contra a mulher: estudo de casos e controles com vítimas atendidas em serviços de urgência e emergência. Caderno Saúde Pública, 2016, 32 (4 e.11414).

19. JEWKES R, et al. Sexual violence. In: Krug EG, Dahlberg LL, Mercy JA, Zwi AB, Lozano R, editores. World report on violence and health Genebra: WHO; 2002, 147-174.

20. LEITE FMC, et al. Violência contra a mulher em Vitória, Espírito Santo, Brasil. Revista de Saúde Pública, 2017, 51, 1-12.

21. LEITE JT, ét al. Enfrentamento da violência doméstica contra crianças e adolescentes a perspectiva de enfermeiros da atenção básica. Revista Gaúcha Enferm., 2016, 37 (2 e. 55796).

22. MENDES KDS, et al. Revisão integrativa: método de pesquisa para a incorporação de evidências na saúde e na enfermagem. Texto Completo Enferm, 2008, 17 (4), 758-764.

23. MINISTERIO DA SAÚDE (BR). Violência intrafamiliar: orientações para a prática em serviço. Brasília: Ministério da Saúde; 2002.

24. PERALVA TR, et al. Violência doméstica na percepção de enfermeiros de serviço de emergência. Reon Facema, 2016, 2 (3), $221-228$.

25. SAPORI LF, SENA LL. Crack e violência urbana. In: Ribeiro $M$, Laranjeira R, organizadores. O tratamento do usuário de crack Porto Alegre: Editora Artmed; 2012, 74-91.

26. SCHRAIBER LB, et al. Prevalênciada violência contra a mulher por parceiro íntimo em regiões do Brasil. Rev Saúde Pública. 2007.

27. SILVA LEL, OLIVEIRA MLC. Características epidemiológicas da violência contra a mulher no Distrito Federal, 2009 a 2012. EpAidemiol. Serv. Saude, 2016, 25 (2), 331-342.

28. SILVA LL, et al. Violência silenciosa: violência psicológica como condição da violência física doméstica. Interface (Botucatu) [online]. 2007, 11 (21), 93-103.

29. SILVA NNF, et al. Atuação dos enfermeiros da atenção básica a mulheres em situação de violência. Enferm. Foco, 2017, 8 (3).

30. SILVA PLN, et al. Práticas educativas sobre violência contra a mulher na formação de universitários. Revista Bioét., 2016, 24 (2), 276-285.

31. SOUZA JA, et al. Fatores associados à violência conjugal em um grupo de mulheres no município de João Pessoa - Paraíba. Tempus, actas de saúde colet, 2016, 10 (2), 81-102.

32. WHO. Global and regional estimates of violence against women: prevalence and health effects of intimate partner violence and non-partner sexual violence. Geneva: World Health Organization; 2013. 